\title{
Kinetics of calcination of partially carbonated particles in a Ca-looping system for
}

\section{$\mathrm{CO}_{2}$ capture}

\author{
I. Martínez ${ }^{\mathrm{a}}$, G. Grasa ${ }^{\mathrm{a}}$, R. Murillo ${ }^{\mathrm{a}}$, B. Arias $^{\mathrm{b}}$, J.C. Abanades ${ }^{\mathrm{b}}$ \\ a Instituto de Carboquímica, Consejo Superior de Investigaciones Científicas (CSIC), \\ Miguel Luesma Castán 4, 50018 Zaragoza, Spain \\ b Instituto Nacional del Carbón, Consejo Superior de Investigaciones Científicas \\ (CSIC), Francisco Pintado Fe 26, 33011 Oviedo, Spain \\ email: imartinez@icb.csic.es, gga@icb.csic.es, ramon.murillo@csic.es, \\ borja@incar.csic.es, abanades@incar.csic.es
}

\begin{abstract}
Post-combustion $\mathrm{CO}_{2}$ capture based on Ca-looping process, CaL, is a promising technology under development based on the reversible reaction between $\mathrm{CaO}$ and $\mathrm{CO}_{2}$ to form $\mathrm{CaCO}_{3}$ and the regeneration of the $\mathrm{CaO}$ by calcination of $\mathrm{CaCO}_{3}$ in a rich $\mathrm{CO}_{2}$ atmosphere. This work is focused on the study of the calcination kinetics with typical solid conditions expected in these systems. Calcination rates of carbonated materials derived from two limestones have been measured at different number of carbonationcalcination cycles, as a function of temperature and $\mathrm{CO}_{2}$ partial pressure. It has been observed that calcination reaction is chemically controlled for particles below $300 \mu \mathrm{m}$ of particle size, as internal mass transfer is negligible even under the presence of $\mathrm{CO}_{2}$ in the reaction atmosphere. Calcination rate (expressed per mol of initial $\mathrm{CaO}$ ) depends on calcination temperature and $\mathrm{CO}_{2}$ partial pressure, whereas $\mathrm{CaCO}_{3}$ content and/or particle lifetime do not affect the reaction rate. The basic kinetic model of Szekely et al. (1970) is shown to be valid to fit the new data. Based on these results it is shown that calcination temperatures between $880-920^{\circ} \mathrm{C}$ could be sufficient to achieve nearly
\end{abstract}


complete calcination conversion at typical solid residence time of CFB calciner reactors (2-3 minutes) in the CaL system.

\section{Introduction.}

Ca-looping process, CaL, is a rapidly developing $\mathrm{CO}_{2}$ capture technology both in postcombustion and pre-combustion $\mathrm{CO}_{2}$ systems (see recent reviews ${ }^{1,2,3}$ ). The reaction of a CaO-based sorbent with $\mathrm{CO}_{2}$ to form $\mathrm{CaCO}_{3}$ and the reverse calcination reaction (mainly in a pure $\mathrm{CO}_{2}$ or $\mathrm{CO}_{2} / \mathrm{H}_{2} \mathrm{O}$ atmosphere) are at the core of all CaL systems.

This work focuses on the CaL system for $\mathrm{CO}_{2}$ capture that was originally proposed by Shimizu et al. ${ }^{4}$, using lime as $\mathrm{CO}_{2}$-sorbent. The system involves the separation of $\mathrm{CO}_{2}$ using the reversible carbonation reaction of $\mathrm{CaO}$ and the calcination of $\mathrm{CaCO}_{3}$ to regenerate the sorbent. A typical configuration for this process would consist of two interconnected circulating fluidized beds (CFB), calciner and carbonator, operating under atmospheric pressure. Flue gases leaving the boiler of an existing power plant are fed into the carbonation unit where the $\mathrm{CO}_{2}$ reacts with the $\mathrm{CaO}$ coming from the calciner to obtain $\mathrm{CaCO}_{3}$. Solids from carbonator are sent back to the calcination unit where $\mathrm{CaCO}_{3}$ is again decomposed to form $\mathrm{CaO}$, which is recirculated to the carbonator, and $\mathrm{CO}_{2}$ as a concentrated gas stream suitable for compression and storage. Since a concentrated $\mathrm{CO}_{2}$ stream is aimed at the exit of the calciner, the equilibrium of $\mathrm{CO}_{2}$ on $\mathrm{CaO}$ (close to $900^{\circ} \mathrm{C}$ for pure $\mathrm{CO}_{2}$ at atmospheric pressure) requires operation at high temperature during calcination. Oxyfuel combustion of coal can be used to supply the calcination energy (Shimizu et al. $^{4}$ ) and higher efficiency options (that do not require a pure $\mathrm{O}_{2}$ stream) have also been proposed (Martinez et al. ${ }^{5}$ and Grasa and Abanades $^{6}$ ).

Most recent studies on sorbent performance have focused on the determination of $\mathrm{CO}_{2}$ carrying capacity of the sorbent (see reviews ${ }^{1,2,3}$ ) in a wide range of conditions and for 
a large variety of materials. This improved knowledge on sorbent performance has facilitated the development of kinetic reaction models suitable for the conditions of interest for the process (Bouquet et al. ${ }^{7}$, Sun et al. ${ }^{8}$, Fang et al. ${ }^{9}$, Grasa et al. ${ }^{10}$ ). High reaction rates between the $\mathrm{CO}_{2}$ in the flue gas and the sorbent particles are certainly necessary in order to design compact $\mathrm{CO}_{2}$ absorbers. The development of suitable particle reaction models has helped in the design of reactor models for the carbonation reactor in the CaL system (Alonso et al. ${ }^{11}$, Lasheras et al. ${ }^{12}$, Romano ${ }^{13}$, Martínez et al. ${ }^{14}$ ). The operation of the carbonator reactor is being experimentally validated at increasing scales, from the preliminary tests carried out at the $10 \mathrm{kWth}$ fluidized-bed carbonator by Abanades et al. ${ }^{15}$ which showed the carbonation reaction of $\mathrm{CaO}$ as a solution to absorb the $\mathrm{CO}_{2}$ from large stationary sources, to the $75 \mathrm{kWth}$ pilot-scale dual fluidized bed system (with a bubbling fluidized bed carbonator) by Lu et al. ${ }^{16}$ to study $\mathrm{CO}_{2}$ capture efficiency in carbonator in fully stable and continuous mode. Charitos et al. ${ }^{17}$ also reported on capture efficiencies above $90 \%$ obtained in a $10 \mathrm{kWth}$ dual fluidized bed facility (bubbling carbonator connected to a CFB calciner) under different operating conditions. Recently, studies carried out in a $30 \mathrm{kWth}$ test facility using two interconnected CFB reactors as carbonator and calciner were presented by Alonso et al. ${ }^{18}$ reporting capture efficiencies between $70 \%$ and $97 \%$ under realistic flue gas conditions. Carbonation efficiency of this CFB carbonator has been also analysed by Rodriguez et al. ${ }^{19}$ as a function of the solid circulation rate, the solid inventory, the average carrying capacity of the $\mathrm{CaO}$ circulating particles, the temperature and the gas velocity in the reactor, reporting on high values in conditions close to that expected in commercial applications. Results obtained in the latest two experimental pilot plants have been validated and compared in a recent published work by Charitos et al. ${ }^{20}$ using the active space time of both installations, with solid residence times below a few 
minutes in the carbonator and calciner in most of the experiments conducted in continuous mode in the interconnected CFB reactors.

In contrast to the increasing knowledge on carbonator performance, little attention has been devoted so far to detailed analysis of the sorbent regeneration reactor coupled to the carbonator in these $\mathrm{CaL}$ systems. An adequate performance of this reactor is obviously essential to demonstrate CaL process viability. But it is usually assumed that this reactor (in its configuration as an oxy-fired CFB combustor) will always be able to operate (adjusting combustion conditions) at sufficiently high temperature to guarantee a very high efficiency in the calcination reaction. Recent experiments performed at a 75 kWth pilot plant by Lu et al. ${ }^{16}$ showed that oxy-combustion of a solid fuel for sorbent regeneration in a CFB reactor allows for a good performance of the CaL process. Oxycombustion of a fuel implies high $\mathrm{CO}_{2}$ concentration in the calciner off-gas around 85 $\%$ vol. as well as flue gas recycle in the range of 50-60 \% and therefore, this will be the environment where the regeneration of the sorbent will have to take place. A larger pilot plant facility of $200 \mathrm{kWth}$ has been built at the University of Stuttgart (Hawthorne et al. ${ }^{21}$ ) to investigate the CaL process under more realistic operating conditions than in the previous lab-scale plant, where energy in the calciner is provided by combustion of $\mathrm{CH}_{4}$ with enhanced air together with electrical heating. In this pilot plant, regenerator has been designed to operate in oxy-fuel mode by burning different types of solid fuels, mainly coal, that will provide further results to evaluate calciner performance of the CaL system. Larger plants have been proposed and built under different projects to operate the calciner under oxy-fuel combustion mode in CFB, not yet largely studied in small scale units. The biggest demonstration CaL plant (1.7 MWth) has been built in La Pereda power plant under the 7th Framework Programme project named 'CaOling' (Development of postcombustion $\mathrm{CO}_{2}$ capture with $\mathrm{CaO}$ in a large testing facility, 
www.caoling.eu). It is expected that this pilot plant will begin operation within the next months and will demonstrate the viability of the whole CaL process ${ }^{22}$.

There are important issues related to the calcination of $\mathrm{CaCO}_{3}$ that are specific to the CaL post-combustion technology referred above, and that have not been addressed so far in the open literature. For typical fuels and experimental conditions it is likely that the calcination environment in the oxy-fired CFB combustor acting as calciner reactor will range between 50 to $80 \%$ vol. of $\mathrm{CO}_{2}{ }^{14}$. Despite the effective heat recovery in CaL systems (Romeo et al. ${ }^{23}$, Ströhle et al. ${ }^{24}$, Hawthorne et al. ${ }^{25}$, Martinez et al. ${ }^{14}$ ) it will always be a design target to minimize energy consumption in this reactor (Rodriguez et al. ${ }^{26}$ ) in order to minimize $\mathrm{O}_{2}$ consumption and associated cost. Coal consumption in the calciner reactor depends on several operation and design variables of the $\mathrm{CO}_{2}$ capture process such as the desired $\mathrm{CO}_{2}$ capture efficiency that is determined by sorbent circulation rates between reactors and fresh sorbent addition. The design temperature in the calciner reactor will always be aimed at a value as low as possible in order to achieve not only effective calcination of $\mathrm{CaCO}_{3}$ coming from the carbonator and the make up flow feed with minimum heat requirements, but also minimum dangers associated with ash issues and minimum sorbent deactivation that tends to increase drastically beyond $950^{\circ} \mathrm{C}$ (Grasa and Abanades $^{27}$ and Gonzalez et al. ${ }^{28}$ ). In general, operation of the calciner at lower temperatures (around or below $900^{\circ} \mathrm{C}$ in atmospheres with sufficient $\mathrm{H}_{2} \mathrm{O}$ content) is favoured also by its proximity to standard operation of CFBC boilers $\left(850^{\circ} \mathrm{C}\right.$ to maximize in situ $\mathrm{SO}_{2}$ capture, see for example review of Anthony and Granatstein ${ }^{29}$ ). But at these low temperatures, the kinetics of the calcination reaction may not be sufficient to achieve the high calcination efficiencies needed in the calciner. In this context, this work is focused on the determination of the 
calcination kinetics to describe the evolution of the carbonate conversion of the typical sorbent of a CaL process.

There is a wide database of literature on the thermal decomposition of $\mathrm{CaCO}_{3}$ in $\mathrm{CFBC}$ environments (Beruto and Searcy ${ }^{30}, \mathrm{Hu}$ and Scaroni ${ }^{31}$, Borgwardt ${ }^{32}$, Garcia-Labiano et al. $^{33}$, Dennis and Hayhurst ${ }^{34}$, Rao et al. ${ }^{35}$ ) that is relevant for this purpose. Calcination kinetics of $\mathrm{CaCO}_{3}$ particles is one of the most investigated inorganic reaction after combustion and has been the subject many studies in a wide range of conditions and applications. However, there is no a consensus about a general reaction mechanism ${ }^{36}$, and for each particular application, semi-empirical models are still used for practical purposes. For desulfurization applications in flue gas combustion environments, several authors assumed that the decomposition of small limestone particles (1-90 $\mu \mathrm{m})$ is chemically controlled (Beruto and Searcy ${ }^{30}$, Hu and Scaroni ${ }^{31}$, Borgwardt ${ }^{32}$ ). For larger particle sizes (below $2 \mathrm{~mm}$ ), Dennis and Hayhurst ${ }^{34}$ also concluded that calcination is controlled by chemical reaction at a sharp interface between $\mathrm{CaCO}_{3}$ and $\mathrm{CaO}$ in a fluidised bed combustor. However some other works have shown evidence of the importance gained by the internal mass transfer resistance with increasing particle size (García-Labiano et al. ${ }^{33}$ ). This work will revisit these reaction models to interpret the experimental results obtained when measuring calcination rates in multi-cycled particles and $\mathrm{CO}_{2}$ rich gas atmosphere that are characteristic of the calciner reactor in postcombustion $\mathrm{CaL} \mathrm{CO}_{2}$ capture systems.

\section{Experimental}

Carbonation and calcination cycles have been carried out in a thermogravimetric analyzer (TGA) suitable to derive reactivity data during carbonation or calcination in long multi-cycle tests. The TGA used in this work has been described in detail elsewhere ${ }^{10}$. The reacting gas mixture $\left(\mathrm{CO}_{2} /\right.$ air $)$ set by mass flow controllers was fed 
into the bottom of a quartz tube placed into a two-zone furnace. External diffusion resistances have been eliminated operating with $2 \mathrm{mg}$ of sorbent and a total gas flow of $1.11 \cdot 10^{-6} \mathrm{~m}^{3} \mathrm{~N} / \mathrm{s}$. Experiments were carried out at atmospheric pressure while temperature and sample weight were continuously recorded on a computer. For each test, sorbent underwent ten calcination/carbonation cycles (12 minutes per cycle). To avoid the decomposition of limestone during the heating up period between carbonation to calcination conditions, the carbonation reaction was carried out at $100 \%$ vol. of $\mathrm{CO}_{2}$ during 8 minutes and the temperature was close to that set in the calcination period. Blank tests determined possible disturbances in sample weight as a result of switching gas density in the gas flow through the reactor. At the end of each test, samples were weighted in a balance in order to check the accuracy of the TGA results and, as a result, it was observed good agreement between sorbent conversion calculated from this weight measured and that evaluated from TGA results.

Two different limestones have been used for the experiments (named A and B in the paper). Four particle size cuts have been tested for limestone A: 75-125 $\mu \mathrm{m}, 125-300$ $\mu \mathrm{m}, 300-600 \mu \mathrm{m}$ and 600-800 $\mu \mathrm{m}$, and one size cut for limestone B: 75-125 $\mu \mathrm{m}$. Both limestones were analysed through an ICP-OES Spectrometer to determine their chemical composition. The limestones presented a residue after loss on fusion of $56 \%$ by weight whose mainly components were $\mathrm{CaO}, \mathrm{MgO}$ and $\mathrm{SiO}_{2}$ (see Table 1). Both limestones were characterised by using a Hg Porosimeter Quantachrome Pore Master to estimate the pore volume and the pore-size distribution and $\mathrm{N}_{2}$ adsorption (Micromeritics ASAP2020) at $77 \mathrm{~K}$ was used to calculate the sorbent surface area by applying the Brunauer, Emmett and Teller equation. Results obtained in these tests together with those obtained for their calcines are shown in Table 1. The effect of three different variables has been analysed in this work: the effect of particle size, calcination 
temperature and $\mathrm{CO}_{2}$ partial pressure on multi-cycle calcination reaction. Preliminary tests were done to analyse the effect of particle size on calcination rate and elucidate the importance of gas diffusion resistances at pore level. These tests were performed for limestone $\mathrm{A}$ at two different $\mathrm{CO}_{2}$ partial pressures, $0 \mathrm{kPa}$ and $50 \mathrm{kPa}$. To derive the kinetic parameters for the calcination reaction including highly cycled particles (ten reaction cycles) and high $\mathrm{CO}_{2}$ concentrations, a set of experiments was carried out analysing the effect that calcination temperature (temperatures tested ranged from $820^{\circ} \mathrm{C}$ to $910^{\circ} \mathrm{C}$ ) and $\mathrm{CO}_{2}$ partial pressure (from $0 \mathrm{kPa}$ to $100 \mathrm{kPa}$ ) have on reaction rates. These tests were focused on the smallest size cut of both limestones as it will be explained in further detail below.

\section{[Table 1]}

[Figure 1]

Several tests were carried out in the TGA with larger quantities of sample, calcining at $900^{\circ} \mathrm{C}$ in air, to obtain sufficient mass for measurements of pore size distribution by mercury porosimetry. Figure 1 is an example of a typical plot of $\mathrm{dV} / \mathrm{dD}$ vs. pore diameter for two samples of limestone B after the first and fifth calcination respectively. It can be seen that the original texture of the first calcine with a rather narrow pore size distribution, evolves towards bimodal distribution typical of samples that have experienced several calcination-carbonation cycles $^{37}$. These measurements were intended to aid in the selection of calcination models as will be discussed below.

In order to give an insight to the possible particle calcination reaction model for the limestones tested, a sample of fresh limestone A (75-125 $\mu \mathrm{m})$ was half calcined at $880^{\circ} \mathrm{C}$ in air and analysed by SEM. Sample preparation was carried out in an inert atmosphere, it was mildly crushed, dispersed on a graphite tab, and gold-coated with a 20-nm-thick film for their observation under scanning electron microscopy. The 
micrographs obtained by SEM are shown in Figure 2 (a) and (b) and will be used to further support the model selection in the next section.

[Figure 2]

\section{Results and discussion}

Preliminary measurements of calcination rates tests were carried out at different particle sizes to check the relative importance of gas diffusion effects in the different pore networks resulting from different carbonation and calcination cycles. Four particle size intervals where used $(75-125,125-300,300-600$ and 600-800 $\mu \mathrm{m})$. Calcination temperature in these tests was fixed at around $880^{\circ} \mathrm{C}$. Two series of experiments were carried out. The first tests were conducted in absence of $\mathrm{CO}_{2}$ in the gas fed to the TGA, so that diffusion effects of $\mathrm{CO}_{2}$ in the pore network of the particles should be more pronounced and easier to detect when changing particle sizes. The second tests were conducted at $50 \%$ vol. of $\mathrm{CO}_{2}$ also for different particle sizes. Figure 3 shows the calcination curves versus time in absence of $\mathrm{CO}_{2}$ for the calcination in the second and eighth cycle, Figures (a) and (b) respectively. As it can be seen for the second calcination, reaction rate is hardly affected by internal diffusion resistance below 300 $\mu \mathrm{m}$ or, in case internal resistance was present, its effect on kinetics would be the same for both sizes. From that size onwards, there is a small effect of particle size on calcination rate due to $\mathrm{CO}_{2}$ internal diffusion resistance that results in a higher calcination time to achieve complete $\mathrm{CaCO}_{3}$ decomposition. As limestone undergoes a higher number of calcination/carbonation cycles, the internal resistance of the $\mathrm{CO}_{2}$ released during calcination sharply diminishes and calcination rate is practically identical even when particles as large as $600 \mu \mathrm{m}$ diameter are used (Figure $3 \mathrm{~b}$ ). Figure 4 shows the results from the tests carried out in presence of $50 \%$ vol. of $\mathrm{CO}_{2}$, which are in qualitative agreement with the results obtained when calcining in air but with 
enlarged differences between curves. Although higher calcination times are required in all cases due to the effect of $\mathrm{CO}_{2}$ on kinetics (as it will be described by reaction model equations), it is appreciated that internal mass transfer resistance continues being negligible below $300 \mu \mathrm{m}$ of particle size from the first cycle as curves for 75-125 and 125-300 $\mu \mathrm{m}$ match up completely. For larger particle sizes $(600-800 \mu \mathrm{m})$ calcination rates are slightly lower which can be considered a sign of both internal resistance to $\mathrm{CO}_{2}$ diffusion in presence of $\mathrm{CO}_{2}$ in the calcination atmosphere and reduced kinetics because of $\mathrm{CO}_{2}$, resulting in longer time to achieve complete calcination.

[Figure 3]

[Figure 4]

From the results obtained in TGA it can be concluded that the calcination reaction of cycled particles in a CFB based post-combustion CaL system, with a particle size below $300 \mu \mathrm{m}$, is chemically controlled since the first cycles. This results in a reaction taking place at the same extent throughout the particles where no relevant particle size effects can be found. This homogeneous character of the reaction is even more pronounced after several calcination/carbonation cycles, as it would be expected from the opening of the pore network as noted in Figure 1. These conclusions are supported by the images obtained by SEM (Figure 2) where it is observed that pores resulted from $\mathrm{CaCO}_{3}$ decomposition are uniformly distributed throughout the particle. In addition, as it has been shown recently by González et al. ${ }^{38}$, CaL system will most likely operate with average particle sizes of $\mathrm{CaO}$ around $90 \mu \mathrm{m}$ due to attrition phenomena. For all these reasons, the determination of the kinetic rate parameters for the calcination reaction models to be used in this work to interpret the available results is focused from this point on the $75-125 \mu \mathrm{m}$ size cut. 
As indicated in the introduction section, different reaction models have been proposed in the literature to describe the calcination reaction in close conditions to those used in the experiments carried out in this work. Homogeneous reaction model throughout the sorbent was assumed by Borgwardt ${ }^{32}$ with particle sizes under $90 \mu \mathrm{m}$. Khinast et al. ${ }^{39}$ applied a modified Random Pore Model, RPM, to the calcination reaction that relates the evolution of the pore structure of the solid during calcination with its conversion. The shrinking core model and the uniform conversion model appeared as suitable reaction models to describe the calcination reaction of fine particles in two extreme conditions. On the one hand, the shrinking core model would be able to describe the calcination of limestones with a very low initial porosity. On the other hand, for solids with a higher initial porosity, the uniform conversion model could be applied. This second scenario is obviously the most adequate for our results, as it has been discussed in the previous paragraphs around the observations in Figures 1-4.

Typical calcination conversion curves vs. time obtained from the multi-cycle experiments are represented in Figure 5 (a) and (b). Considering that $\mathrm{X}_{\text {calc }}$ and $\mathrm{X}_{\text {carb }}$ are the $\mathrm{CaCO}_{3}$ content exiting and entering the calciner (both expressed in moles of $\mathrm{CaCO}_{3}$ per mol of $\mathrm{Ca}$ ), respectively, $\left(\mathrm{X}_{\text {carb }}-\mathrm{X}_{\text {calc }}\right)$ is the $\mathrm{CaCO}_{3}$ decomposed per mol of Ca. For the calcination of pure $\mathrm{CaCO}_{3}$ (that implies $100 \%$ of $\mathrm{CaCO}_{3}$ content), ( $\mathrm{X}_{\text {carb }}-\mathrm{X}_{\text {calc }}$ ) varies between 0 to 1 . For the calcination of a sorbent that has been carbonated up to the maximum carrying capacity in the previous carbonation-calcination cycle, $\mathrm{X}_{\mathrm{N}-1}$, the value of $\left(\mathrm{X}_{\text {carb }}-\mathrm{X}_{\text {calc }}\right)$ changes from 0 to $\mathrm{X}_{\mathrm{N}-1}$.

[Figure 5]

According to Figure 5 calcination rates (slopes of $\mathrm{d}\left(\mathrm{X}_{\text {carb }}-\mathrm{X}_{\text {calc }}\right) / \mathrm{dt}$ for $\left(\mathrm{X}_{\text {carb }}-\mathrm{X}_{\text {calc }}\right)<\mathrm{X}_{\mathrm{N}}$ 1) are constant with different cycle number for a given calcination temperature and $\mathrm{CO}_{2}$ concentration in the gas phase. However, in order to facilitate the interpretation of the 
experimental results with a definition of conversion independent of cycle number, the $\mathrm{CaCO}_{3}$ decomposed on every cycle has been normalised with the maximum carbonate content achievable in the previous cycle as follows:

$$
f_{\text {calc }}=\frac{\text { moles of } \mathrm{CaCO}_{3} \text { decomposed }}{\text { moles of } \mathrm{CaO} \cdot X_{N-1}}=\frac{\left(X_{\text {carb }}-X_{\text {calc }}\right)}{X_{\text {carb }}}
$$

In this way, $f_{\text {calc }}$ ranges on every cycle from 0 to 1 . The evolution of $\mathrm{X}_{\mathrm{N}-1}\left(\right.$ or $\left.\mathrm{X}_{\mathrm{N}}\right)$ with $\mathrm{N}$ has been widely studied, and it has been found that can be described according to Equation 2 for a variety of limestones and reaction conditions, with a deactivation constant $\mathrm{k}$ of 0.52 and a sorbent residual molar conversion $\mathrm{X}_{\mathrm{r}}$ of $0.075^{27}$.

$$
\mathrm{X}_{\mathrm{N}}=\frac{1}{\frac{1}{\left(1-\mathrm{X}_{\mathrm{r}}\right)}+\mathrm{kN}}+\mathrm{X}_{\mathrm{r}} \quad \mathrm{k}=0.52, \mathrm{X}_{\mathrm{r}}=0.075\left(\mathrm{~T}_{\text {calc }}<950^{\circ} \mathrm{C}, \mathrm{t}_{\text {calc }}<20 \mathrm{~min}\right)
$$

Figure 6 represents the normalisation of the experimental conversion data for the conversion curves included in Figure 5 (a) and (b).

[Figure 6]

The resulting plots can then be fitted to a kinetic model for calcination embracing the observations reported in previous paragraphs. As indicated above, the materials tested in this work follow during calcination an apparent homogeneous conversion pattern at particle level. Fang et al. ${ }^{40}$ proposed an equation based on the classic grain model of Szekely and Evans ${ }^{41}$ to describe the calcination reaction of CaO-based sorbents in CaL applications, that is in principle consistent with an homogeneous model at particle level:

$$
\frac{d f_{c a l c}}{d t}=k_{c, N} \cdot\left(1-f_{c a l c}\right)^{2 / 3} \cdot\left(C_{e q}-C_{C O 2}\right)
$$

In this model, each carbonated particle is assumed to be formed by uniformly sized nonporous spherical grains of $\mathrm{CaCO}_{3}$ and $\mathrm{CaO}$ that calcine following a shrinking core model under chemical reaction control (Equation 3). A similar expression was also used to fit fast carbonation rates in a previous work (Grasa et al. $^{42}$ ), although more elaborate 
versions of this carbonation model have been published more recently (Grasa et al. ${ }^{10}$ ) based on RPM (developed by Bathia and Perlmutter ${ }^{43-44}$ ) to account for slow reaction regimes and transitions regimes. We have attempted data fit with equation 3 in this work because of its simplicity and sufficient good quality of the fit for the whole range of calcination curves. Furthermore, it is already known that grain model predictions match those made by the RPM under chemical reaction control and, as well, when moderate transport resistances are included for porous particles with typical values of reaction surface area, total pore length and porosity ${ }^{43-44}$.

Equilibrium $\mathrm{CO}_{2}$ concentration $\left(\mathrm{C}_{\mathrm{eq}}\right)$ has been evaluated from the molar fraction of $\mathrm{CO}_{2}$ in the equilibrium, $f_{\mathrm{e}}$, by using Equation 4 where $\mathrm{T}$ is the operation temperature (in ${ }^{\circ} \mathrm{K}$ ) and $\mathrm{P}$ is the total system pressure (in atm) $)^{45}$.

$$
f_{e}=\frac{10^{(7.079-8308 / T)}}{P}
$$

To determine the kinetic parameter of the calcination reaction, different experiments including up to 10 calcination/carbonation cycles each, have been carried out for both limestones varying the calcination temperature from 820 to $910^{\circ} \mathrm{C}$, and reaction atmosphere from $0 \mathrm{kPa}$ to $100 \mathrm{kPa}$ of $\mathrm{CO}_{2}$. The calcination conversion of limestone particles on each cycle $\mathrm{N}$, was calculated from the experimental data on weight changes measured with the TGA analyser during reaction according to Equation 1, normalized with the maximum carbonate content achievable in the previous cycle. Combining Equations 1 and 3, calcination rate (per mol of $\mathrm{Ca}$ ) will be given by:

$$
\frac{d\left(X_{c a r b}-X_{c a l c}\right)}{d t}=k_{c}\left(1-\left(\frac{X_{c a r b}-X_{c a l c}}{X_{c a r b}}\right)\right)^{2 / 3} \cdot\left(C_{e q}-C_{C O 2}\right)
$$

A fitting exercise has been carried out to determine kinetic constant of calcination reaction $k_{c}$, using experimental results obtained in the TGA set up described in the experimental section. The kinetic constant was determined in each cycle from the 
conversion curves at different calcination temperatures. An Arrhenius representation was plotted for the individual values of $\mathrm{k}_{\mathrm{c}}$ obtained and pre-exponential factor, $\mathrm{k}_{\mathrm{c} 0}$ $\left(\mathrm{m}^{3} / \mathrm{kmol} \cdot \mathrm{s}\right)$, and activation energy, $\mathrm{E}_{\mathrm{ac}}(\mathrm{kJ} / \mathrm{mol})$, were determined from the ordinate in the origin and the slope, respectively, according to Equation 6.

$$
k_{c}=k_{c 0} \cdot \exp \left(-E_{a c} / R \cdot T\right)
$$

The values of $\mathrm{k}_{\mathrm{c} 0}$ and $\mathrm{E}_{\mathrm{ac}}$ have been included in Table 1 for both limestones. Activation energies obtained over the temperature range 820 to $910^{\circ} \mathrm{C}$ for Limestone $\mathrm{A}, 112.4$ $\mathrm{kJ} / \mathrm{mol}$, and Limestone B, $91.7 \mathrm{~kJ} / \mathrm{mol}$, are similar and as it could be expected as both limestones had similar internal structure and pore size evolution pattern. These activation energies are somehow in the lower range of those reported in the literature, between 110 to $210 \mathrm{~kJ} / \mathrm{mol}$ (Gallagher and Johnson ${ }^{46}$, Borgwardt ${ }^{32}$, Garcia-Labiano et al. $^{33}$, Dennis and Hayhurst ${ }^{34}$, Rao et al. ${ }^{35}$ ) obtained for temperatures in a range of 600 to $900^{\circ} \mathrm{C}$ However they are in close agreement with values obtained by García-Calvo et al. ${ }^{47}$ and Romero-Salvador et al. ${ }^{48}$ who reported activation energies for calcite decomposition of around $109 \mathrm{~kJ} / \mathrm{mol}$ and stated this low value was due to the presence of impurities and/or physical processes, such as sintering. The limestones tested in this work present at least $4 \%$ wt. of impurities, that could act as catalyst and result in slightly low activation energies. The fact that Limestone B present higher amount of impurities than Limestone A could also explain its lower activation energy with respect to the other limestone. But it is beyond the scope of this work to explain in more detail the source of these variations in apparent activation energies, because from a practical point of view it is sufficient to have for each limestone a suitable set of pre-exponential factor and activation energy for equation 5 .

[Figure 7] 
Figure 7 shows the effect of calcination temperature on reaction rate for limestone $\mathrm{B}$ during fifth calcination in absence of $\mathrm{CO}_{2}$ (Figure a) and in presence of $25 \mathrm{kPa}$ of $\mathrm{CO}_{2}$ (Figure b). As expected, this figure shows how increasing calcination temperature results in a higher reaction rate, and also that the presence of $\mathrm{CO}_{2}$ reduces the reaction rate for a given temperature. $\mathrm{CO}_{2}$ partial pressures close to those given by the equilibrium (Equation 4) result in a dramatic reduction in reaction rate. This is the case of calcination temperature at $825^{\circ} \mathrm{C}$ under a $25 \mathrm{kPa}$ of $\mathrm{CO}_{2}$ partial pressure in the reaction atmosphere that lead to a complete calcination times well above $2 \mathrm{~min}$.

With respect to the dependence of the calcination reaction with the presence of $\mathrm{CO}_{2}$, the right hand side term in Equation 3 or 5 has been applied in the past with success by several authors to describe this dependence (Hu and Scaroni ${ }^{31}$, Rao et al. ${ }^{35}$, Silcox et al. ${ }^{49}$, Fuertes et al. ${ }^{50}$ ). Figure 8 shows the effect of $\mathrm{CO}_{2}$ partial pressure on calcination rates for a given temperature $\left(890^{\circ} \mathrm{C}\right.$ in this case) and for both limestones. Figure 8 (a) represents the calcination conversion of a cycle number 2 for limestone A. Figure 8 (b) represents the calcination conversion of a cycle number 5 for limestone B.

[Figure 8]

The model also presents good agreement between prediction and experimental data under calcination conditions close to the equilibrium as it can be seen in Figure 9. The difference between the molar fraction of $\mathrm{CO}_{2}$ given by the equilibrium composition $\left(f_{\mathrm{e}}\right)$ and the $\mathrm{CO}_{2}$ in the reaction atmosphere $\left(f_{\mathrm{CO} 2}\right)$ has been varied between 0.05 and 0.08 for limestone B for two different temperatures. This is an indirect validation of the accuracy of the equation of Baker ${ }^{45}$ (equation 4) for the equilibrium in this temperature range and the accuracy of the experimental set up (sample temperatures in the TG plate and gas composition).

[Figure 9] 
Despite of its simplicity, the model predictions represented in Figures 6 to 9 by solid lines reproduce with reasonable accuracy all the experimental data presented in this work. The model proposed is able to predict the calcination conversion of the sorbent in a range of conditions of interest for the CaL process and different calcination/carbonation cycles. Furthermore, the integration of equation 5 provides an expression for evaluating the full calcination time $\left(t^{*} \mathrm{c}\right)$ needed to achieve complete decomposition of $\mathrm{CaCO}_{3}$ (or what is the same, to achieve $0 \%$ of $\mathrm{CaCO}_{3}$ content) for particles of any $\mathrm{CaCO}_{3}$ content $\mathrm{X}_{\mathrm{carb}}$ that yields:

$t_{c}^{*}=\frac{3 \cdot X_{c a r b}}{k_{c} \cdot\left(C_{e q}-C_{C O 2}\right)}$

[Figure 10]

Figure 10 represents this full calcination time, $\mathrm{t}_{\mathrm{c}}{ }^{*}$, for some illustrative examples using the limestone A kinetic data. As can be seen with the lines with symbols, calcination of pure limestone would require a substantial reaction time and/or higher temperatures of calcination for a given ambient partial pressure of $\mathrm{CO}_{2}$ and temperature. However, the calcination of typical solids from the carbonator (with a molar carbonate content of 15 $\%$ in the example of this figure) requires much lower calcination times. This may have important positive implications for the CaL system. As it has been discussed in the introduction, calcination temperature has a great influence in the energy requirements of the CaL system and therefore in the economics. It is observed from Figure 10 that even temperature below $900^{\circ} \mathrm{C}$ are clearly enough for achieving complete calcination under $\mathrm{CO}_{2}$ concentrations typical of the $\mathrm{CaL}$ calcination environment at residence times typical in the circulating fluidised bed calciner. Therefore, lower temperatures than expected in previous simulation publications (Shimizu et al. ${ }^{4}$, Martínez et al. ${ }^{5}$, Lasheras et al. ${ }^{12}$, Romano ${ }^{13}$, Martínez et al. ${ }^{14}$, Ströhle et al. ${ }^{24}$, Hawthorne et al. ${ }^{25}$, Rodriguez et al. ${ }^{26}$, Yongping et al. ${ }^{51}$,) could be considered. Coal and oxygen consumption could be 
optimised, $\mathrm{SO}_{2}$ capture in the calciner gets closer to the optimum conditions and a wider variety of fuels (ash softening issues) can be used in the calciner at lower calcination temperatures.

\section{Conclusions}

Calcination kinetics of two different limestones that have experienced repetitive calcination/carbonation cycles have been determined in a TGA analyser. It has been experimentally observed that the calcination reaction is chemically controlled as internal mass transfer resistance is negligible up to $300 \mu \mathrm{m}$ particle size, even in presence of $\mathrm{CO}_{2}$ in the reaction atmosphere. In this way, calcination reaction (expressed per mol of initial $\mathrm{CaO}$ ) depends on calcination temperature and $\mathrm{CO}_{2}$ partial pressure, whereas $\mathrm{CaCO}_{3}$ content and/or particle lifetime do not affect the reaction rate. The calcination reaction in multi calcination/carbonation cycles has been described with a reaction model based on a grain model that considers a particle formed by grains that follow a shrinking core model under chemical reaction control and the kinetic constant of the reaction has been determined. The model proposed is able to predict the calcination conversion of the sorbent at calcination conditions of interest for the Ca-looping process and should contribute to its scaling up.

\section{Acknowledgements}

This work is partially supported by the European Commission under the 7th Framework Programme (CaOling project). Financial support for I. Martinez during her PhD studies is provided by the FPU programme of the Spanish Ministry of Research and Innovation.

\section{Nomenclature}

$\mathrm{C}_{\mathrm{CO} 2}\left(\mathrm{kmol} / \mathrm{m}^{3}\right)$ : Concentration of $\mathrm{CO}_{2}$ in the gas phase

$\mathrm{C}_{\mathrm{eq}}\left(\mathrm{kmol} / \mathrm{m}^{3}\right)$ : Equilibrium concentration of $\mathrm{CO}_{2}$ in the gas phase

$\mathrm{E}_{\mathrm{ac}}(\mathrm{kJ} / \mathrm{mol})$ : Activation energy of kinetic constant of $\mathrm{CaCO}_{3}$ calcination 
$f_{\text {calc }}$ : Fraction of $\mathrm{CaCO}_{3}$ decomposed to $\mathrm{CaO}$ and $\mathrm{CO}_{2}$ in the calcination reaction with reference to the moles of $\mathrm{CaCO}_{3}$ coming from former carbonation (it varies from 0 to 1 in every cycle)

$f_{\mathrm{CO} 2}$ : Molar fraction of $\mathrm{CO}_{2}$ in the gas phase

$f_{\mathrm{e}}$ : Molar fraction of $\mathrm{CO}_{2}$ in the equilibrium (according to Baker ${ }^{42}$ )

k: Deactivation constant of $\mathrm{CaO}$

$\mathrm{k}_{\mathrm{c}}\left(\mathrm{m}^{3} / \mathrm{kmol} \cdot \mathrm{s}\right)$ : Kinetic constant of $\mathrm{CaCO}_{3}$ calcination

$\mathrm{k}_{\mathrm{c} 0}\left(\mathrm{~m}^{3} / \mathrm{kmol} \cdot \mathrm{s}\right)$ : Pre-exponential factor of kinetic constant of $\mathrm{CaCO}_{3}$ calcination

$\mathrm{N}$ : Number of calcination/carbonation cycles

P: Pressure

PCO2: $\mathrm{CO}_{2}$ partial pressure

$\mathrm{R}(\mathrm{J} / \mathrm{mol} \cdot \mathrm{K})$ : Ideal gas constant

T: Temperature

$\mathrm{t}_{\mathrm{c}}{ }^{*}(\mathrm{~s})$ : Time needed to achieve full calcination for a particle of any $\mathrm{CaCO}_{3}$ content $\mathrm{X}_{\text {calc }}$ (moles $\mathrm{CaCO}_{3} / \mathrm{mol} \mathrm{Ca)}$ ) $\mathrm{CaCO}_{3}$ content exiting the calciner

$\mathrm{X}_{\text {carb }}$ (moles $\mathrm{CaCO}_{3} / \mathrm{mol} \mathrm{Ca)}$ : $\mathrm{CaCO}_{3}$ content entering the calciner:

$\mathrm{X}_{\mathrm{r}}$ : Residual conversion of $\mathrm{CaO}$ after many hundred cycles

\section{References}

(1) Harrison, D.P. Ind. Eng. Chem. Res. 2008, 47, 6486-6501.

(2) Anthony, E.J. Ind. Eng. Chem. Res. 2008, 47, 1747-1754.

(3) Dean, C.C.; Blamey, J.; Florin, N.H.; Al-Jeboori, M.J.; Fennell, P.S. Chem. Eng. Res. Des. 2011, 89, 836-855.

(4) Shimizu, T.; Hirama, T.; Hosoda, H.; Kitani, K.; Inagaki, M.; Tejima, K. Trans. IChemE. 1999, 77 (Part A), 62-68. 
(5) Martínez, I.; Murillo, R.; Grasa, G. Rodríguez, N.; Abanades, J.C. Int. J.

Greenhouse Gas Control. 2011, 5, 498-504.

(6) Grasa, G.; Abanades, J.C. Chem. Eng. Sci. 2007, 62, 619-626.

(7) Bouquet, E.; Leyssens, G.; Schönnenbeck, C.; Gilot, P. Chem. Eng. Sci. 2009, 64, 2136-2146.

(8) Sun, P.; Grace, J.R.; Lim, J.; Anthony, E.J. Chem. Eng. Sci. 2008, 63, 57-70.

(9) Fang, F.; Li, Z.S.; Cai, N.S. Energy Fuels. 2009, 23, 207-216.

(10) Grasa, G.; Murillo, R.; Alonso, M.; Abanades, J.C. AIChE J. 2009, 55 (5), 12461255.

(11) Alonso, M.; Rodríguez, N.; Grasa, G.; Abanades, J.C. Chem. Eng. Sci. 2009, 64, 883-891.

(12) Lasheras, A.; Ströhle, J.; Galloy, A.; Epple, B. Int. J. Greenhouse Gas Control. 2011, 5, 686-693.

(13) Romano, M. Energy Procedia. 2009, 1, 1099-1106.

(14) Martínez, I.; Murillo, R.; Grasa, G.; Abanades, J.C. AIChE J. 2011, 57 (9), 25992607.

(15) Abanades, J.C.; Anthony, E.J.; Lu, D.Y.; Salvador, C.; Álvarez, D. AIChE J. 2004, 50 (7), 1614-1622.

(16) Lu, D.Y.; Hughes, R.W.; Anthony, E.J. Fuel Process. Technol. 2008, 89, 13861395.

(17) Charitos, A.; Hawthorne, C.; Bidwe, A.R.; Sivalingman, S.; Schuster, A.;

Spliethiff, H.; Scheffknecht, G. Int. J. Greenhouse Gas Control. 2010, 4, 776-784.

(18) Alonso, M.; Rodríguez, N.; González, B.; Grasa, G.; Murillo, R.; Abanades, J.C. Int. J. Greenhouse Gas Control. 2010, 4, 167-173.

(19) Rodríguez, N.; Alsono, M.; Abanades, J.C. AIChE J. 2011, 57 (5), 1356-1366. 
(20) Charitos, A.; Rodríguez, N.; Hawthorne, C.; Alonso, M.; Zieba, M.; Arias, B.; Kopanakis, G.; Scheffknecht, G.; Abanades, J.C. Ind. Eng. Chem. Res. 2011, 50, 96859695.

(21) Hawthorne, C.; Dieter, H.; Bidwe, A.; Schuster, A.; Scheffknecht, G.; Unterberger, S.; Käß, M. Energy Procedia. 2011, 4, 441-448.

(22) Sánchez-Biezma, A.; Ballesteros, J.C.; Díaz, L.; de Zárraga, E.; Álvarez, F.J.; López, J.; Arias, B.; Grasa, G.; Abanades, J.C. Energy Procedia. 2011, 4, 852-859. (23) Romeo, L.M.; Abanades, J.C.; Escosa, J.M.; Paño, J.; Giménez, A.; SánchezBiezma, A.; Ballesteros, J.C. Energy Convers. Manage. 2008, 49, 2809-2814.

(24) Ströhle, J.; Galloy, A.; Epple, B. Energy Procedia. 2009, 1, 1313-1320.

(25) Hawthorne, C.; Trossmann, M.; Galindo Cifre, P.; Schuster, A.; Scheffknecht, G. Energy Procedia. 2009, 1, 1387-1394.

(26) Rodríguez, N.; Alonso, M.; Grasa, G.; Abanades, J.C. Chem. Eng. J. 2008, 138, 148-154.

(27) Grasa, G.; Abanades, J.C. Ind. Eng. Chem. Res. 2006, 45, 8846-8851.

(28) González, B.; Grasa, G.S.; Alonso, M.; Abanades, J.C. Ind. Eng. Chem. Res. 2008, 47, 9256-9262.

(29) Anthony, E.J.; Granatstein, D.L. Prog. Energy Combust. Sci. 2001, 27, 215-236.

(30) Beruto, D.; Searcy, A.W. J. Chem. Soc., Faraday Trans. 1. 1974, 70, 2145-2153.

(31) Hu, N.; Scaroni, A.W. Fuel. 1996, 75 (2), 177-186.

(32) Borgwardt, R.H. AIChE J. 1985, 31 (1), 103-111.

(33) Garcia-Labiano, F.; Abad, A.; de Diego, L.F.; Gayán, P.; Adánez, J. Chem. Eng. Sci. 2002, 57, 2381-2393.

(34) Dennis, J.S.; Hayhurst, A.N. Chem. Eng. Sci. 1987, 42 (10), 2361-2372.

(35) Rao, T.R.; Gunn, D.J.; Bowen, J.H. Chem. Eng. Res. Des. 1989, 67, 38-47. 
(36) L'vov, B.V.; Polzik, L.K.; Ugolkov, V.L. Thermochim. Acta. 2002, 390, 5-19.

(37) Alvarez, D.; Abanades, J.C. Ind. Eng. Chem. Res. 2005, 44, 5608-5615.

(38) González, B.; Alonso, M.; Abanades, J.C. Fuel. 2010, 89, 2918-2924.

(39) Khinast, J.; Krammer, G.F.; Brunner, Ch.; Staudinger, G. Chem. Eng. Sci. 1996, 51 (4), 623-634.

(40) Fang, F.; Li, Z.S.; Cai, N.S. Energy Fuels. 2009, 23, 207-216.

(41) Szekely, J.; Evans, J.W. Chem. Eng. Sci. 1970, 25, 1091-1107.

(42) Grasa, G.; Abanades, J.C.; Alonso, M.; González, B. Chem. Eng. J. 2008, 137, $561-567$.

(43) Bathia, S.K.; Perlmutter, D.D. AIChE J. 1980, 26 (3), 379-386.

(44) Bathia, S.K.; Perlmutter, D.D. AIChE J. 1981, 27 (2), 247-254.

(45) Baker, R. J Appl. Chem. Biotechnol. 1973, 23, 733-742.

(46) Gallagher, P.K.; Johnson, D.W. Thermochim. Acta. 1973, 6, 67-83.

(47) García-Calvo, E.; Arranz, M.A.; Letón, P. Thermochim. Acta. 1990, 170, 7-11.

(48) Romero-Salvador, A.; García-Calvo, E.; Benitez Aparicio, C. Thermochim. Acta. 1989, 143, 339-345.

(49) Silcox, G.D.; Kramlich, J.C.; Pershing, D.W. Ind. Eng. Chem. Res. 1989, 28, 155160.

(50) Fuertes, A.B.; Marbán, G.; Rubiera, F. T. I. Chem. Eng-Lond. 1993, 71 (A), 421428.

(51) Yongping, Y.; Rongrong, Z.; Liqiang, D.; Kavosh, M.; Patchigolla, K.; Oakey, J. Int. J. Greenhouse Gas Control. 2010, 4, 603-612. 


\section{FIGURES}

Figure 1. Pore size distribution for limestone $\mathrm{B}$ after first and fifth calcination of the sorbent.

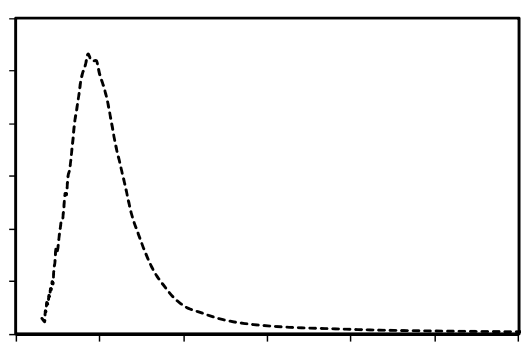

